\title{
Kimberlite Emplacement Processes Interpreted from Lac de Gras Examples
}

\author{
Kirkley, M.B., Kolebaba, M.R., Carlson, J.A., Gonzales, A.M., Dyck, D.R., and \\ Dierker, C.
}

\author{
BHP Minerals Canada, Ltd., \#8-1699 Powick Road, Kelowna, B.C., V1X 4L1, Canada
}

One hundred kimberlite bodies have been discovered on the BHP-Dia Met property in the Lac de Gras region of Canada's Northwest Territories. In a number of the pipes, drilling has encountered crater facies kimberlites to substantial depths below the surface, e.g. to a depth of $400 \mathrm{~m}$ in a pipe with a $150 \mathrm{~m}$ diameter. This presents the opportunity to re-examine kimberlite emplacement models. Existing models have developed largely through study of South African pipes where crater facies kimberlite is rarely encountered and was postulated to occur only in the uppermost levels of pipes (Hawthorne, 1975). Emplacement models presented here are derived from kimberlite lithologies and textures observed in drill core from BHP-Dia Met kimberlites. These interpretations are preliminary and meant to serve as working models; additional drilling and mine development will provide more information to refine these models.

Four stages of kimberlite emplacement are envisaged; these may occur separately and successively, or may overlap:

1. Explosive eruption causes expulsion of host rock and creates an open pipe. Host rock debris, along with variable amounts of pyroclastic kimberlite, is deposited at the crater rim. The newly formed pipe may remain open for some period of time as evidenced by layers of water lain sediments, some organic-rich, encountered by deep drill intercepts in some pipes.

2. Pyroclastic kimberlite derived from subsequent eruption(s) begins to fill the pipe and accumulates as rim deposits. This variety of kimberlite consists predominantly of olivine macrocrysts in ash matrix. Size and compositional layering may be present, indicating segregation of coarse/fine and heavy/light components during eruption and deposition. Host rock xenoliths and crustal debris such as wood and mudstone fragments are relatively rare.

3. Epiclastic kimberlite and crustal debris eroded from the crater rim are deposited into the pipe. This variety of fill consists of olivine macrocrysts and kimberlite ash mixed with abundant crustal materials such as host rock granitic and mudstone fragments, their derivatives such as quartz, feldspar and mica grains, and surficial organic debris such as wood. Sorting and layering are common.

4. Diatreme and/or hypabyssal facies kimberlite intrudes into pyroclastic/epiclastic materials. Intrusive relationships between facies types are evidenced by sharp contacts and by.inclusion-host and cross-cutting relationships, including diatreme facies overlying crater facies lithologies. Alternatively, gradational contacts between crater and diatreme facies are observed in some pipes. Gradational contacts suggest that diatreme facies kimberlite emplacement followed shortly after crater facies kimberlite deposition, before the volcaniclastics compacted and lithified. 
Complete expulsion of host rock, which allows for subsequent infilling of an open pipe, is proposed to be a function of intense fluid pressure which built up in front of the kimberlite magma advance. Such high fluid pressures are proposed, in turn, to be a function of the impervious nature of the Slave Province granitic crust which prevented a decrease in fluid pressure prior to eruption. Fluid associated with the kimberlite magma was therefore able to penetrate to a minimum distance beneath the surface whilst maintaining maximum pressure. Near surface fracturing followed by breakthrough of this high pressure fluid ejected virtually all pre-existing material out of the pipe. A few of the pipes contain relatively abundant xenoliths of granitic host rock in diatreme facies breccias which indicate incomplete expulsion of host rock. This may be a result of decreased fluid pressures, e.g. due to leakage of fluid along fractures, such that intense pressure required to expel all host rock was not available.

Epiclastic deposition resulted from erosion of the rim deposits. Fine material occurs as thin mudstone beds in some pipes and suggests that rain water winnowed fines from rim deposits and washed them into the pipe. This winnowing appears to have sufficiently destabilized rim deposits to permit mass wasting of coarse-grained kimberlite, crustal xenoliths and organic debris into the pipe. Well-sorted and graded beds, tens of meters thick, indicate subaqueous deposition in some pipes.

Whether pyroclastic or epiclastic kimberlite is the dominant pipe lithology depended on the quantity of kimberlite associated with the initial fluid breakthrough. Availability of substantial quantities of kimberlite allowed pipes to fill with dominantly pyroclastic and/or reworked pyroclastic material eroded from the rim. Emplacement of limited quantities of pyroclastic kimberlite resulted in pipes filled with dominantly nonkimberlitic epiclastic materials. Alternating pyroclastic eruptions and epiclastic deposition from the rim produced sequences of interbedded crater volcaniclastics.

Diatreme facies kimberlite is rare in the BHP-Dia Met pipes, relative to South African pipes. Crosscutting diatreme facies intrusives represent separate kimberlite magma pulses with limited access to the surface due to overlying crater deposits. Diatreme facies kimberlite grades into overlying crater deposits at some occurrences, producing pipes more akin to the Hawthorne (1975) model.

Hypabyssal kimberlite intrudes overlying crater deposits in a number of pipes and completely fills the Leslie pipe. Only a very restricted amount of diatreme facies kimberlite has been found at this locality. The age of the Leslie kimberlite is similar to that of nearby pipes filled with crater facies material. It is unlikely that the Leslie pipe has been substantially eroded. Apparently, hypabyssal magma completely displaced the pre-existing pipe fill to a high level in the pipe.

\section{References}

Hawthorne, J.B., 1975, Model of a kimberlite pipe: Physics and Chemistry of the Earth, 9, p. $1-15$. 


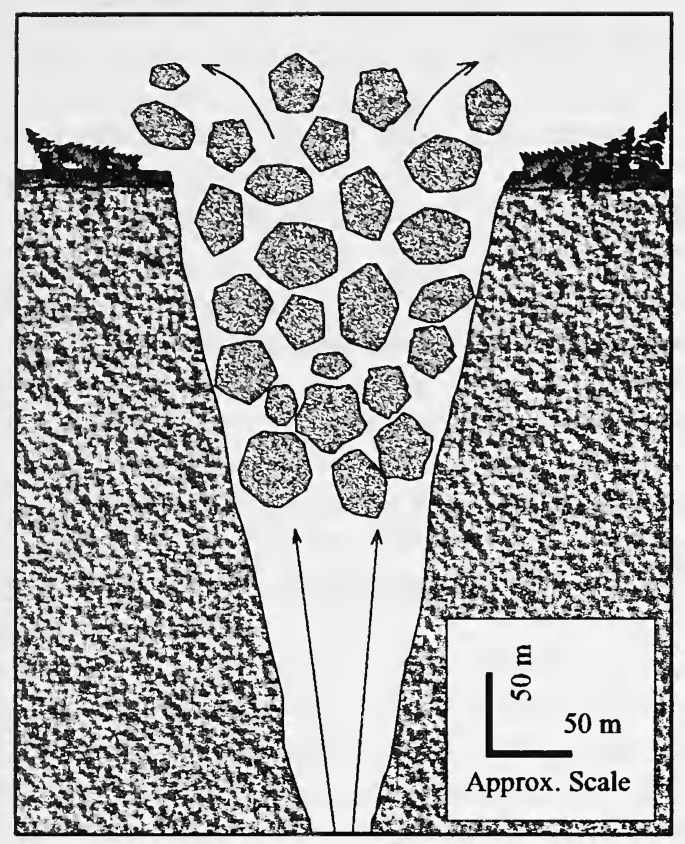

1) High pressure fluid fractures and blasts through basement rocks, removing host material and creating an open diatreme.

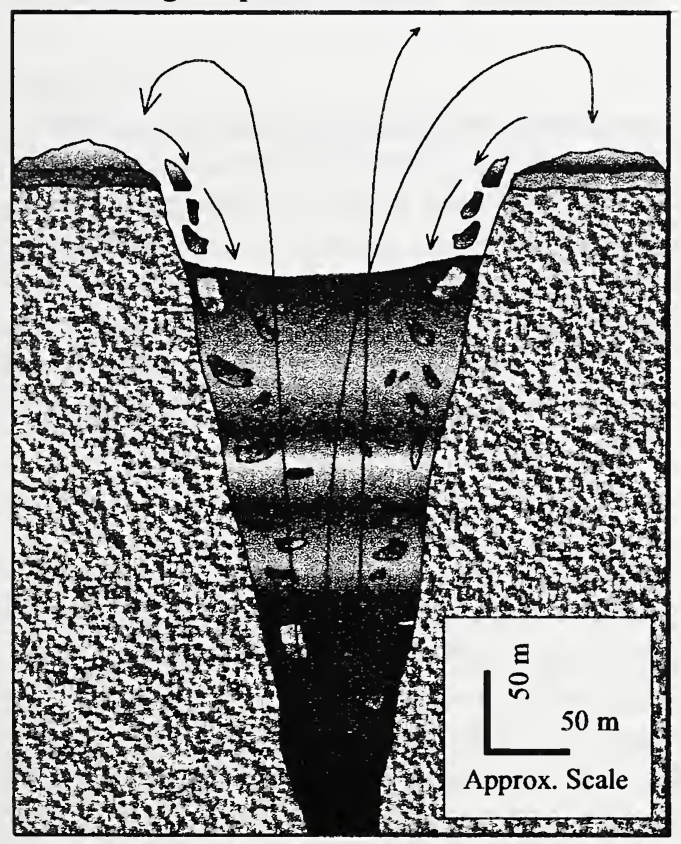

3) Epiclastic components, e.g. wood, mud, sand and host rock xenoliths, erode into the pipe from the rim deposits. Mixing and interlayering with volcaniclastics from (2) may occur.

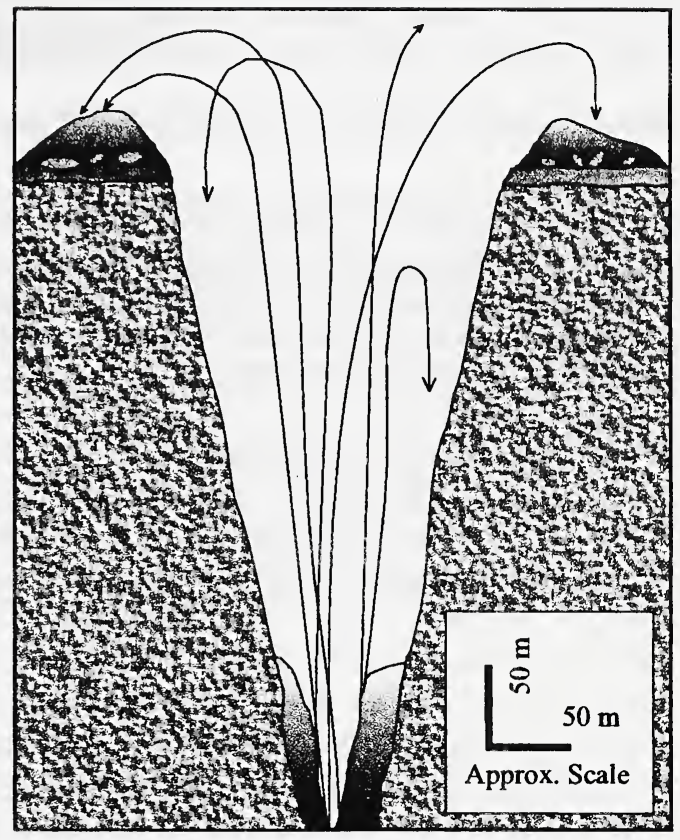

2) Pyroclastic kimberlite, dominated by broken olivine macrocrysts, pellets, close-packed texture and ash matrix, fills the pipe.

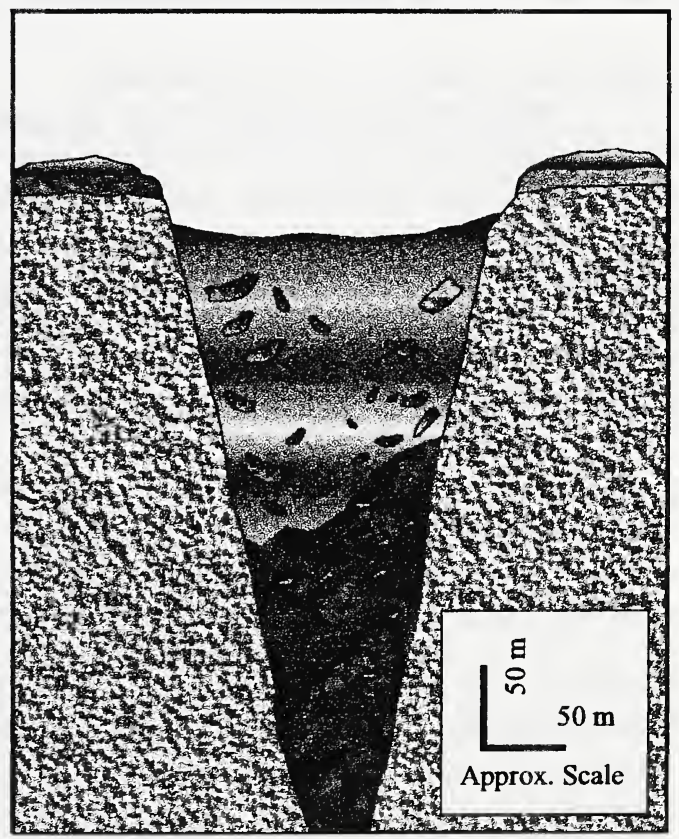

4) Hypabyssal and/or diatreme kimberlite intrudes the volcaniclastics. In at least one case, hypabyssal kimberlite fills the entire pipe.

NOTE: Clasts and layering are diagramatic only and not to scale. 